\title{
The Flux of Experience and The Aesthetic Transferential Psychology in Isidore Okpewho's call me by My Rightful Name (2004)
}

\author{
Souleymane Diallo
}

Phd student / A R C I V Doctoral School Postcolonial and African Studies Laboratory Cheikh Anta Diop University, Dakar, Senegal

DOI: $10.36348 /$ sijll.2021.v04i01.004

| Received: 01.01.2020 | Accepted: 08.01.2020 | Published: 16.01.2021

*Corresponding author: Souleymane Diallo

\section{Abstract}

The psycho-social approach implemented in the line of this narrative puts into view, the author's undertaking of analyzing the rapport of the institutions of representations and the institutions of technology. Within this respect, the involvement of verbal text, throughout Okpewho's dynamic to redefine the basic stylistic effects and the distinctive nature of systems that determine the forms of knowledge displays parameters of interrogation pertaining to the reality of the individual, issues of creation, significance, memory and figure. Thus, by transgressing conventional perception of written text, Okpewho moves beyond unconscious perception to ingrain, a formal and substantial relation as it regards intellectual representation. The object and the search of figures of consciousness that underline the scope of Call Me By My Rightful Name constitutes a psychoanalytical method stressing on a realm of self-reconnection and re-appropriation. Then, through a material truth and an objective reality, Okpewho attempts to withdraw the written cultural system superimposed upon oral traditional cultures. Therefore, the purpose of this article becomes an analytic method within which the emphasis is put on the how the values of truth of the individual as regard its cultural, social and linguistic context determine the unity of the concrete reality of the cognitive psychology and social organization of the African primitive traditions.

Keywords: Institution, Representation, Psychology, Affective, Metaphysic, Oral Tradition, Written Text, Performance, Meta-communication, Reality, Materiality, Perception.

Copyright () 2021 The Author(s): This is an open-access article distributed under the terms of the Creative Commons Attribution 4.0 International License (CC BY-NC 4.0) which permits unrestricted use, distribution, and reproduction in any medium for non-commercial use provided the original author and source are credited.

\section{INTRODUCTION}

The conception of understanding the self, through the course of the contemporary socio-political and cultural method of re-centering identity, appears to connect itself with the domain of experience, memory, reason and imagination. In effect, these affective perceptions, and representative sensations ground a new intellectual approach, and an intention to strengthen its symbolic realm by emphasizing on the external, physical, sensible structures; otherwise, on psychological, affective portents. Therefore, the outline of a psycho-sociological and cultural identity fluctuation provides an intellectual, rational response that unveils the opinions, the emotional states and affective tenets of the individual. Correspondingly, through the intellective construction of the self, the dynamic to reach the truth of thought and existence, appealingly, puts the emphasis on the interpretation of unqualified representativeness and necessary beliefs.

In this run, socio-cultural and constitutional anthropology becomes a pure intellection, and a composed figure, in the perspective to display the formal causes and the material truth inside a consistent system of thought and experience. Contained by the dynamic of this respect, and following the material substance of the socio-cultural organization of those societies labeled as primitive, Isidore Okpewho, through his work Call Me By My Rightful Name, develops a new theoretical and methodical approach concerning written texts and verbalized texts. Basically, this author's capacity to organize a material time, an intellective atmosphere, and a real presence of characters, reveals a specific shrillness and observation in relation to the structure, and the preservation of African oral tradition in contemporary Western conception of objective reality of intellection.

Indeed, in the distorted negro-world where the individual is molded following primitive states, and exile condition, Okpewho's Call Me By My Rightful Name, becomes a structured system that deconstructs the primitivism and cultural inadequacy imposed on the unity of the concrete reality of African verbalized 
tradition. Thus, the dimensions of immaterial, the metaphysical authenticity, and the transformation of reality, through achievement and self-consciousness become Okpewho's means of transcending and challenging the conventional intellectual principles. Through a cultural historian, ethno-linguist and musicologist stand, Okpewho seeks to redefine the cultural identity of the individual around the rigorism of oral tradition although the scheme of globalization imposes a different thinking and accomplishment.

In this respect, the main line of this article emphasis on the construction of a material object and imagination, and the configuration of a homogenous perception to strengthen the reality of verbal literary forms. Furthermore, through the aesthetic plurality that withstands this work, this paper gets through an analysis of the relational and temporal wholesome customs of sensibilities within language, performance and the significance of cosmogony demonstrates the cognitive and social organization of the African nonscientific cultures. The main axes of this paper evolve around three points. In the next section, I discuss the notion of performance and the physiological and psychological process of form and identity. In the succeeding section, I deal with the process of ideas, judgment, emotion and the materialization of willpower, and an ideal prototypical of awareness and action. In the third section, I question the contrasting figures and effects of verbalized texts within Okpewho's work par rapport the individualistic contemporary literary texts.

\section{Topical and Oral Perceptive Psychology}

The act of deconstructing the Western written, scientific and individualistic culture inside the expressive, traditional and empirical collective and perceptive organization of the African societies propels Isidore Okpewho in an intimate process of discussing the materiality, and reality of the consequence and singularity of oral tradition. Undeniably, through his construction of temporal and relational values that contrasts with the creative and modern Western intellection, Okpewo moves away the yoke of the strictly intellectual echo of culture to display the demonstrative approach that traditional constituencies bestow on the domain of civilization. Therefore, in the course of an objective psychology and on qualitative and quantitative determination of facts, the involved characters in the line of Call Me By My Rightful Name, seem to enthrall quantitative identity, as a method that the individual attains through active involvement subsequent to a custom of thought and action. By this way, the oral features one observes in this Okpewho's work entail the scheme of values as the whole materiel causes, formal relation and substantial distinction that release the domain of thought and collective consciousness. Likewise, the inlaying of the Yoroba main philosophical and religious book the Ifa and its different $O d u$ components goes beyond a merely intellectual superimposition; it definitely bears a differential psychology that its instruction and didacticism are efficiently based on the cognizance of myth language and performance. It is within this respect, we understand Wanjala arguments:

It is no longer possible for a creative writer to reveal the creative ethos of his community unless he integrates his activities into the creative dynamism of his community. In fact the creative writer has a lot to learn from the traditional artist who has always worked as an insider within his community. In defining literature, critics who omit the oral artist and who separate the study of written literature from the study of oral literature become restrictive and discriminatory [1].

Through the realm of oral principles involved in this written literary process, Okpewho deliberately commits the range of his psychoanalysis approach of historical and cultural reconnection with a rational and ontological psychology. Through physical sensibilities, affective perception and representative awareness, the creativity of the oral domain focuses mainly on the reconstruction of the beyond of the individual. Indeed, memory as the receptacle of knowledge is put in the scheme of an evolutional standpoint that exceeds the Western scientific and artistic analytical psychology. In this manner, throughout the run of Call Me By $M y$ Rightful Name, the evolving oratory genus becomes substantially, an interpersonal transcendent and progressive heritage that underlines the inner essence of the being, and the preternatural values of African evolutions. In this perspective, the heterogeneousness of religious, mystical and artistic experience, and the consequences of a reality out of the borders of the primitive African world instill a psychological distance and the abolition of an intellectual process:

In reviewing the evidences gathered in separate sessions with father and son, Fishbein had detected certain strands that led to contiguous points in family history, but needed a clinching thread to link them up into a coherent picture... Still, he was sure he was on to something that might prove their surest bet for a solution: if they could capture the words Otis chanted during his spasms, a lot of the threads might convert into some meaningful picture [2].

Definitely, Otis jr Hampton' case tells much about that differential psychology and characterology. Challenged by a great trial of an unknown reality, this slave descendant protagonist finds a disjunctive and exclusive system of reconnecting his internal reality and external reality. Over and done with the straitjacket of his Western individualistic and rational education, the advent of the mystery of redemption on his twenty first 
birthday signals the process of renaissance, or the rehabilitation of the truth of a material and spiritual reality that was shifted inside his inner reality. Subsequently, through essence topics, toponymic reconstruction, rhythms and verbal significance, Otis jr character bears the weight of the reality of rediscovering the formative facts of the history of his African civilization and embedding the added value of those oral tradition in the inner essence of his reality. Within this respect, music otherwise acoustic effects and language throughout its profoundness effects become the reality and the appearance of his transmigration revolution. Therefore, the purpose and the imperative of Otis' marching back on his Yoroba ancestors land defines another order of reality within which restoring the memory of the past goes straightforwardly by naming and performing and readapting social mysticism. For that reason, Okpewho furthers this point:

Will you prepare to enter, again, the sacred grove of the god? The glare of his face is hard on the eye: Ogun, spare me the sight of your blood-shot eyes. Ogun is a mad god who still makes demands of us after a thousand years. And where do we find him? Where battle's joined. Where wrangling's done. Where torrents of blood flow till they choke the fields. Warrior god, who sharpens his sword on his teeth. Avenging god, who takes from the strong and gives to the weak. Ogun of the hunters feeds on the dog: to him, a dog for sacrifice. And will you, servant of Ogun, prepare to enter, again, the hallowed grove of your god? [2].

In that order, this psychological journey attests another surrealist investment within Okpewho, through his focus on African oral tradition disintegrates the credence to the superior reality of written cultures; and then establishes, the sensitive scope of grasping the realm of fundamental philosophical interrogation concerning the sphere of the beginning. Through the depth of his theoretical and methodical inquiries to understand the issues of identity and reconnecting the umbilical cord between the African Diaspora and the reality of their African cosmogony, Okpewho's creation and expression process observes psychological forces, as the dominant receptacle within which to analyze the real functioning of thought and moral and aesthetic concern. Indeed, standing as a cultural historian examining activities, pure psychological response, and processes of achievement in a plurality of characteristics, Okpewho intentionally involves his old twin female characters Kehinde and Taiwo in the dynamic to present the weight and the temporal and spiritual connection between oratory, history and selfrecreation. This relational conception of reality becomes a coherent, and a material nature through the scheme of mastering communication systems and signifying processes and the act of performance. This stand is correspondingly highlighted by Walter J. Ong when he writes that:

In this sense, all sound, and especially oral utterance, which comes from inside living organisms, is 'dynamic'... The fact that oral peoples commonly and in all likelihood universally consider words to have magical potency is clearly tied in, at least unconsciously, with their sense of the word as necessarily spoken, sounded, and hence power-driven. Deeply typographic folk forget to think of words as primarily oral, as events, and hence as necessarily powered: for them, words tend rather to be assimilated to things, 'out there' on a flat surface. Such 'things' are not so readily associated with magic, for they are not actions, but are in a radical sense dead, though subject to dynamic resurrection [3].

By this way, through the aesthetic and ethical cognitive organization of this empirical societies, gender justice becomes a reality, indeed, the twin because of their age, experiences and as the repository of memory, and the manifestation and transferential cannon of history conceal themselves from the limited lifetime affective and representative withdrawal. Similarly, through the range of oral tradition that Okpewho has ingrained in the ground of his creative writing, women in Yoroba community and particularly, the twin appears as the sap and the intellectual value of society. Therefore, beyond the substandard living conditions, they are authorized voices that harbor a definite aptitude to function in variability important scale.

\section{The Status of Spoken Word and Formal Speaking}

The figurative language inserted in the progress of this Okpewho's Call Me by My Rightful Name, reveals the attraction, and the variety of the cohesive forces that institute a multiplicity of constituent, developed in the structuring of verbalized texts. In effect, the form and the content of this oral reality yield a bold understanding of the assortments of logical and rational intellection, extracting therefore, the individual from the conventional burden of written text. Correspondingly, throughout the established introspective psychology, and the evolution of the individual inside the reality of a new avatar, the significance and distinctiveness of orality becomes an abstraction, an imaginary within the historical and mythological references determine the specific features of conception. It is in this perspective, the psycho-social identity reconstruction introduced through the esoteric intellectual essence of this narrative demonstrates that, the orality of the most African cultures reinforce the idea of consideration on features of human conditions. Therefore, the cognizance of oral tradition and the familiarity of written text through their differences and 
interactions require a synchronic approach, in the run to determine, the pure quality and the essential principle of orature. This point is furthered when Okpewho writes:

Whether they were smiling at my crude handling of the poetry of the chant, or they were sympathizing with the tough job I was doing handling an unfamiliar tradition, I didn't try to find out. But it was clear even Olu needed some practice himself. He had heard the text once or twice from the tape, and some of the phrases were obviously familiar to him from his experience as a drummer... I had to read the text a few times before he could feel comfortable with its structure... He seemed to be spacing his drum strokes in such a way as to punctuate my reading. Even at those points where he struck his drum notes to follow my text, he didn't seem to be playing the same notes my text was saying [2].

By this manner, the psycho-historical approach, and the diachronically instruction that Okpewho utilizes in his method of generating a new understanding of cultural identity rehabilitation inscribe, the realm of orature inside a manifestation, wherein the quintessence of a moral and a political order define a pure model of intellection. Subsequently, the knowledge and the functional analogy and psychological analogy of orality, and the consciousness of the self, go beyond the familiarization of phenomenological perception. Indeed, the intellectual representation inserted throughout the realm of orality, organizes an experimental knowledge of psychophysiological and meta-moral object that results to an uninterrupted apperception. Within this respect, through the transformational components of the sphere of oral tradition Okpewho attempts to carry out a functional approach, and the introduction of new scientific etymological bases of orality, in the run to unveil, a new universal rapport of meaning. Within this respect, Tanure Ojaide declares that:

However, a people's experience is so diverse that it is not limited to "authentic" or pristine features. The African reality is diverse and ever-changing and it is expansive enough to accommodate what Africans do in their own different ways. Hybridisation inevitably occurs in the course of a people's history, as that of Africans, and that is an integral aspect of the people's experience. The African identity, therefore, is an ongoing process, like the African culture, and is not fixed on marble but is dynamic - it absorbs new features, even as it discards some of its own old ways. Thus, literary works in non-African languages by Africans that express the African experience and sensibility belong to the multifarious tradition of African literature(s) [4].
Thus, the status of spoken word becomes throughout the narrative structures and the appearing narration stage of this work, a yawning and a multifarious character, which makes available imageries and evaluations of transformation in psychohistorical and socio-political constructions. Therefore, inside the material truth of the spoken word, Okpewho invaluably describes the centrality of the material substance of orality through temporal spiritual and material exchanges. Correspondingly, oral tradition moves further the domain of human language; it encompasses then, the different human means of communication, which involves human faculties to experience the feeling that material, figurative and abstract objects produce. The basic plurality of sensation and the structural image of the world of awareness introduce a practical and hierarchical moral sense that involves the status of spoken word within a sphere of orientation and cultural identity equilibrium. The form and the particular properties of the act of thought and the object of spoken word sustain a functional macro-transformational system within which the implied author of Call Me By My Rightful Name, brings about a discourse of resources, a force of a material and spiritual movement that instill a moral and intellectual shift. As Ruth Finnegan stated in his work of The How Literature:

With all their controversies and multiplicities, the central insight from these studies of orality is a far-reaching one: oral forms are not only comparable to written literature in the minimum sense of being reproducible as written texts paralleling recognized written genres, but also have their own qualities in which performance and declamation aloud and to an audience are of the essence. This has rightly challenged the Eurocentric and high-art paradigm of literature as the norm by which all forms of verbal art are judged, and allowed a greater appreciation of the literary reality of many African and Asian forms as well as of popular genres outside the traditional European canon [5].

Correspondingly, through the distorted reality of the verbal content that stamped Otis' involuntary convulsive reaction, Okpewho shows the materialization of the possibility of another process of communication inside the production of an act of authenticity, which designates material changes and psycho-moral deconditioning. In effect, through Doctor Fishbein's clinical psychological method to grasp Otis' peculiar spoken word, it becomes obvious that the Western essential principles of psychoanalysis do not actually present consequences with the fantastical and idea connotations of Otis' inner reality. In the line to adapt the reality of his new experience to the conditions of the reality lays down by the external dynamic, Dr 
Fishbein acknowledges the technical sense and the affective phenomena required to grasp the intellectual reaction that guaranties the methodical value, the affects and the sensibilities of the oral sphere:

Fishbein set about trying to make sense of what he had captured on tape...Although Olatunji's music was fairly audible in the background; it did not much bother the doctor. Indeed, he welcomed it as a context within which some sense might be made of the young man's predicament. Unfortunately, neither he nor his assistants had any clue how to begin transcribing the text of Otis' chant. Fishbein and his team were familiar with what in the profession went by the term "xenoglossy" - or, in the case of Otis's chant, what more recent scholar had called "recitative xenoglossy." But how would they go about dealing with a language none of them could even identify as one? [2].

Within this respect of understanding the relations of orality and the individual and the consequences of those associations, Okpewho puts into perspective the affective and representative sensation and determinative fundamentals that emphasis on language, music, divination, and on the absorption of the natural, familial environment. Therefore, by extracting the nature of Otis from the literate universe, from Massachusetts to the Yorobaland Ijoko Ode, the involvement of Olantunjy the drum master, Akinwunmi the chief Babalawo inscribes a psycho-affective process within which acoustic properties, and verbal universe bring Otis to explore the truthful image of his nature and then to achieve his affective truth throughout the real social structures of his primitive intellectual canon. In this scheme of work, the formal relation and substantial advantages of the orality order yields a materiel fact assessment that strengthens the view that formal speaking in its essence should be straightly or incidentally interconnected to the phenomenon of representation and motivation of sound where revolutionary idiom finds its real object and factual awareness.

\section{Text, Music and Meta-Communication}

Through the accepted Western models of text, as a methodical object of analysis, Okpewho inserts a gathering of procedures and new characteristics, which make available an innovative theoretical conception as regard rational intellectual perception. In this run, the realm of written text undergoes a macro-structural transformation, and a quality and aesthetic functional variation within which the African oral tradition becomes a constant scheme of analysis. Consequently, the immediate consciousness of the external and inner reality of verbal art within its micro-structural features defines new possibilities of intellection and expression. Obviously, the immersion of orature in the run of the
Western model of text appears as a system of affirmation, which eludes the effects of a psychological conditioning, and ingrains a truth and the actuality of an Identity. Throughout the gathering of variable elementary facts, text following its written procedures ceases to be the only intellective and determinative medium of self-recognition. This point is efficiently pointed out by Emmanuel Obiechina as he argues that:

... Rather, a synthesis takes place in which characteristics of the oral culture survive and are absorbed, assimilated, extended, and even reorganized within a new cultural experience. Also, vital aspects of the oral literature are absorbed into an emerging written literature of greatly invigorated forms infused with vernacular energy through metaphors, images and symbols, more complex plots, and diversified structures of meaning. Such a happy synthesis is possible insofar as certain conditions are present at the meeting point of the oral and written traditions, including the extent to which the synthesizing artist, that is the storyteller or poet, is well rooted in the oral rhetorical forms or narrative traditions, the extent of the familiarity... [6].

Subsequently, inside the narrative structures of this work, Okpewho unveils that the extension of the reality of thought in the manner to analyze and to deepen the consciousness and thought of a reality, discloses a positional organism, formulations and fields of investigation. These facts involve theories that move beyond phenomenological analysis based on the underpinning of primitive societies. Certainly, from the deep seeded identity crisis that characterizes individual or collective representation, Okpewho efficiently puts the emphasis on the original imaginaries, the intermediary state, and the imaginative liberties of the symbolic institutions of the traditional African societies. Accordingly, inside the descriptive style inserted in this narrative, and the musical methodical real-life experience that with its aesthetic abstraction questions, the representative memory changes in the intimate scheme of written text, Okpewho in his way to grasp the identity of the signified correspondences and designated objects brings in speculative and empirical perspective underlining the constituent suppression of the psychosociological institution. As Ngugi wa Thiong'o has pointed out:

... The Devil was clad in a silk suit, and he carried a walking stick shaped like a folded umbrella. On his head there were seven horns, seven trumpets for sounding infernal hymns of praise and glory. The Devil had two mouths, one on his forehead and the other at the back of his head. His belly sagged, as if it were about to give birth to all the evils of the world. 
His skin was red, like that of a pig. Near the Cross he began to tremble and turned his eyes towards the darkness, as if his eyes were being seared by the light. He moaned, beseeching the people not to crucify him, swearing that he and all his followers would never again build Hell for the people on Earth [7].

Thereby, through an interpretative criticism of text and verbal art, Call Me By My Rightful Name, establishes a transformative metaphysical dynamic within the respect, psychoanalysis organization of text and events guaranties the transferential relation and the symbolism of the African oral tradition par rapport features of disarticulations and historical mutation processes. Hence, references to traditional rituals, dance and music bear a metaphorical system of expression, which sees Western doctrine and endogenous perception of text as a contradictory intervention, a superimposition of obscure sensation designating African education and civilization as primitive. Through the vitality and fertility of oral art, Okpewho moves out of the realm of adventurism, and then puts the stress on the sociological and psycholinguistic limits, and the behaviors of the inner forces of those doctrines. Thus, in the perspective of an introspective psychology, through the exegeses theoretical field of primary process laws, and the effective trait of imaginary constitution, the pure moral and political manifestation of music through its exogenous and biological rhythm expurgates the advent of Western civilization in African order of cultures:

... I began chanting the text. The three of us danced to it, Olu playing a reprise to each line... Another tremor came towards the end, at the point where the old performance was disrupted by the slave raiders. In fact, I had some difficulty with that point in the text during our rehearsals, but thought I had mastered it. Here at the real event, it came up again. Olu noticed that I hesitated, and shouted to me in Yoroba to "hold it down." I closed my eyes and belted out the proper transitional line instead of the words I used to say, calling for help... It gives me deep personal satisfaction to set it down as the defining text of our family [2].

Consequently, with the practice of rituals, ceremonial songs, sacrifices and religious acts, the reality and the invention of the imaginary of oral tradition becomes within the inter-psychology and intra-structure of this narrative a strategic status quo connected to a legitimate ancient prescription that strives for its fulfillment outside the Western force of illusion and realities. It becomes obvious that through the intrinsic paralinguistic system of orality established in the run of this narrative, Okpewho displays variability of gathering processes of significant exchanges that go beyond the Western reality of ideas, conventionalism and epiphenomenalist materialism. In effect, all the way through the essence of understanding language, rehabilitating the reality of history through act of performances, Okpewho inscribes the formal and objective reality of verbal text inside a dynamic relation of meta-communication, expression and signification. The esoteric order and secrete instructions of transmission of knowledge, thought and ideas follows a particular and a differentiating dynamic that its original style defines specific methodologies as regards experience, reality and psycho-affective and intellective processes.

\section{CONCLUSION}

The narrative scheme of Call Me By My Rightful Name gets through a methodical intellectual construction with hypothetical and synthetic features, which involves a new epistemological approach as regard the dynamic structures of psycho-sociology and genetic theory of consciousness. By focusing on the different ideas, and organized abstract concepts of Western's concern about the origin of human cultures, Isidore Okpewho unveils that African oral tradition abides within its esoteric status a transferential relation that stands as an intention and moral action within which culture is taught and transmitted.

However, the Western disarticulation of the real of civilization and their perception of affective, representative and determinative acts of consciousness installs all the way through Okpewho's creative writing a normative logical reaction concerning the domain of cultural assimilation and hybridity. Therefore, the exhibition of an affective reality of the African verbalized text becomes a politico-scientific discourse within the perception of evolution and the intrinsic development of history. Without a doubt, through apodictic reasoning and discursive method, Okpewho emphasizes on the manner intellectual perception and sensation inside the functionalism of African verbal arts structurally re-orders the individual reality perception, the objective reality of language, and the formal reality of culture.

Respectively, the deepness effects and perception dimensions in the course of Call Me By My Rightful Name, yield an ideal model within which the individual, language and culture define a new sphere of awareness as it concerns the maturity of nation. The analytical and logical relational features that underline the run of the essence of orature bring a particular system of integration within psycho-social construction and cultural transmission depends effectively on selftime relation and familiarity. Consequently, African oral tradition and particularly the Yoroba cosmogonal system and its gathering organized unit object of thought, become a corroborated organism of 
socialization, material representation, expressionism and collective order structuring.

\section{REFERENCES}

1. Wanjala, C. L. (2003). The growth of a literary tradition in East Africa.

2. Okpewho, I. (2004). Call me by my Rightful Name. Africa World Press.

3. Finnegan, R. H. (2005). The how of literature. Oral Tradition, 20(2), 164-187.
4. Ojaide, T. (2009). Examining canonisation in modern African literature. Asiatic: IIUM Journal of English Language and Literature, 3(1), 1-20.

5. ONG, Walter, J. (2005). Orality and Literacy: The technologizing of the word, London and New York, Routledge, 32

6. Obiechina, E. (1992). Narrative proverbs in the African novel.

7. Wa Thiong'o, N. (2017). Devil on the Cross (Vol. 5). Penguin. 